\title{
Trypanosomosis, Its Risk Factors, and Anaemia in Cattle Population of Dale Wabera District of Kellem Wollega Zone, Western Ethiopia
}

\author{
Habtamu Biyazen, ${ }^{1}$ Reta Duguma, ${ }^{2}$ and Mebratu Asaye ${ }^{2}$ \\ ${ }^{1}$ College of Agro-Industry and Land Resource, Haramaya University, P.O. Box 226, Chiro, Ethiopia \\ ${ }^{2}$ College of Veterinary Medicine and Agriculture, Addis Ababa University, P.O. Box 34, Debre Zeyit, Ethiopia \\ Correspondence should be addressed to Habtamu Biyazen; habtambiyazen@gmail.com
}

Received 4 May 2014; Revised 20 August 2014; Accepted 1 September 2014; Published 16 September 2014

Academic Editor: Nora Mestorino

Copyright ( $) 2014$ Habtamu Biyazen et al. This is an open access article distributed under the Creative Commons Attribution License, which permits unrestricted use, distribution, and reproduction in any medium, provided the original work is properly cited.

Cross-sectional study was conducted in Dale Wabera district of Kellem Wollega zone, Western Ethiopia, to determine the prevalence of bovine trypanosomosis and to evaluate association of bovine trypanosomosis to anaemia. Blood samples collected from 384 randomly selected cattle were subjected to parasitological and haematological analysis. For the parasitological survey, blood samples were examined using a buffy coat technique. The packed cell volume (PCV) value of each animal was also measured using hematocrit reader. The overall prevalence of trypanosomosis was $2.86 \%$. The most common trypanosome species identified were Trypanosoma congolense (63.64\%) followed by T. vivax (27.27\%) and T. brucei (9\%). The prevalence showed no significant difference in susceptibility between sex categories, age groups, and different body conditioned animals. The overall anaemia prevalence in the area was $19.27 \%$. The anaemia prevalence was significantly higher in trypanosome positive cattle (54.54\%) than in noninfected animals $(18.23 \%)(P<0.05)$. The mean PCV value of the infected animals was lower $(22.36 \% \pm 7.39 \%)$ compared to noninfected animals $(27.86 \pm 5.38 \%)$. There was statistically significant difference $(P<0.05)$ in the PCV values of infected and noninfected animals. In conclusion, this study confirmed that trypanosomosis poses a threat to cattle production in the area and also contributed to the occurrence of anaemia.

\section{Introduction}

Trypanosomosis is a widely spread protozoan disease complex which affects cattle and other wide range of hosts in subSaharan Africa. The course of the disease may run from a chronic long lasting to an acute and rapidly fatal depending on the vector-parasite-host interactions. The disease is mainly characterized by intermittent fever, progressive anaemia, and loss of condition of susceptible hosts which if untreated leads to heavy mortalities [1]. The etiological agent of the disease is unicellular flagellated protozoan parasite of a genus Trypanosoma. Trypanosomes are blood borne unicellular protozoan parasites dwelling in various body and tissue fluids. The parasite is known for more than a century, but still control of the disease remains elusive [2].

Several species of hematophagous tsetse flies of the genus Glossina are the vectors of African trypanosomosis and are responsible for cyclical transmission of the parasitic protozoan between numerous vertebrate hosts. The vector is distributed over wide range of habitats covering about 10 million square kilometers of potential grazing lands in 37 countries which are rendered unsuitable for livestock breeding and farming across the African content [3], exposing 160 million cattle to the risk of anaemia, emaciation, and death and 55 million people to the risk of fatal sleep [4]. As a result agriculture revolution which is a key element in the fight against poverty and the improvement of food security in developing countries failed in tsetse infested areas of subSaharan Africa [5].

In Ethiopia, trypanosomosis is one of the most important diseases that limit livestock productivity and agricultural development due to its high prevalence in the most arable and fertile land of southwest and northwest part of the country 
following the greater river basins of Abay, Omo, Ghibe, and Baro [6]. Currently about $220,000 \mathrm{~km}^{2}$ areas of the abovementioned regions are infested with five species of tsetse flies, namely, Glossina pallidipes, G. morsitans, G. fuscipes, G. tachinoides, and G. longipennis [7]. More than 10 million heads of cattle in Ethiopia are at risk of variable degrees of trypanosomosis at any time of the year, of which six million are tsetse borne [8]. A number of studies have been so far undertaken in different parts of the country to determine the magnitude of this economically important disease [9-12]. Nevertheless, there are no published studies which assess the prevalence of this disease in Dale Wabera district.

The distribution of trypanosomes is dynamic due to climatic change, ecological disturbances, and human interventions. Some tsetse infested areas are scarce in infrastructure and devoid of human settlements. In such areas sufficient information is lacking about the status of trypanosomosis. Even in already studied areas updating the prevalence and status of the disease have paramount importance for understanding the epidemiology of the disease, to facilitate the choice of suitable control methods, and to help in planning for development programs in the area. Therefore, the objectives of this study were to determine the prevalence of bovine trypanosomosis in Dale Wabera district and to evaluate association of bovine trypanosomosis with anaemia.

\section{Materials and Methods}

2.1. Study Area. The study was conducted in Dale Wabera district of Kellem Wollega zone of Oromia regional state, Western Ethiopia, during late rainy season. The altitude of the area ranges from 1100 to 1800 m.a.s.l. The mean minimum and maximum temperature are $11.0-15.5^{\circ} \mathrm{C}$ and $26.1-34^{\circ} \mathrm{C}$, respectively. The agroclimate of the area alternates between long summer rain fall (June to September) and winter dry season (December to March) with annual rainfall ranging from 1300 to $1600 \mathrm{~mm}$. The livelihood of the society largely depends on mixed livestock and crop production. The total land cover of the district is about $1132.02 \mathrm{~km}^{2}$ of which $424.77 \mathrm{~km}^{2}$ is infested by tsetse flies [7].

2.2. Study Animals. The animals used for this study were local zebu cattle (Bos indicus), which are usually kept under an extensive husbandry system. The studied cattle were herded together during the day time and returned to their individual owner's farmstead each evening. Their age was categorized into three age groups ( $<2$ years, $2-5$ years, and greater than five years) based on dentition and the body condition score was grouped into poor, medium, and good conditioned animals based on the appearance of ribs and dorsal spines applied for zebu cattle [13].

2.3. Sample Size Determination. The animals were sampled randomly involving both sexes, all age groups, and all types of body conditions. The desired sampling size was calculated according to the formula given by [14]. As there have been no published studies reported in this area, the sample size was determined based on the expected prevalence of $50 \%$, confidence level of $95 \%$, and $5 \%$ desired absolute precision. As result a total of 384 cattle were sampled from ten different locations (villages) in the district.

\subsection{Study Methodology}

2.4.1. Packed Cell Volume (PCV) Determination. Blood samples were obtained by puncturing the marginal ear vein with a lancet and collected directly into a pair of heparinised capillary tubes. After centrifugation at 12,000 rpm for $5 \mathrm{~min}$ in a microhaematocrit centrifuge, the capillary tubes were placed in a haematocrit reader and the length of the red cells column was expressed as a percentage of the total volume of blood. Animals with PCV less than $24 \%$ were considered to be anaemic [4].

2.4.2. Buffy Coat Technique (BCT). Heparinised capillary tubes, containing blood samples, were cut using a diamond tipped pen $1 \mathrm{~mm}$ below and $3 \mathrm{~mm}$ above the buffy coat after centrifugation. The content of the capillary tube was expressed onto a glass slide, then covered with cover slip, and examined under $\times 40$ objective and $\times 10$ eye piece for movement of parasite. Trypanosome species were identified according to their movement in wet film preparations as provided by [4].

2.5. Data Analysis. Prevalence was analyzed by determining total positive cases out of the total number of animals sampled. Infection rate on the basis of sex, age, and body condition was compared using $\chi^{2}$ test (chi-square). Mean PCV in parasitemic and aparasitemic animals was compared using $t$-test. Significance test was set at 5\% alpha and 95 confidence interval.

\section{Results}

3.1. Parasitological Findings. Out of 384 cattle examined 11 $(2.86 \%)$ were found to be infected with trypanosomes. The prevalence in terms of trypanosome species was $1.82 \%$ T. congolense, $0.78 \%$ T. vivax, and $0.26 \%$ T. brucei. The proportion of trypanosome species was $63.64 \%$ (7/11) T. congolense, $27.27 \%$ (3/11) T. vivax, and 9\% (1/11) T. brucei (Figure 1). During study period mixed infection was not detected.

Prevalence of Trypanosomosis according to Age, Sex, and Body Condition. The prevalence of trypanosomosis was higher in males (3.64\%) as compared to female animals $(1.45 \%)$ (Table 1). However, the difference was not statistically significant $(P>0.05)$. The highest prevalence was observed in the adult animals greater than 5 years old (Table 1) and the variation in prevalence between the different age groups was also not statistically significant $(P>0.05)$. The prevalence of trypanosomosis between body condition scores was $3.37 \%$ in poor, $2.81 \%$ in medium, and $2.61 \%$ in good body conditioned animals and it was statistically not significant $(P>0.05)$ as indicated in Table 1. 
TABLE 1: Prevalence of bovine trypanosomosis according to sex, age, and body condition score in Dale Wabera district.

\begin{tabular}{|c|c|c|c|c|c|}
\hline Host related risk factors & Number of examined cattle & Number of infected cattle & Prevalence (\%) & $\chi^{2}$ & $P$ value \\
\hline \multicolumn{6}{|l|}{ Sex } \\
\hline Female & 13 & 2 & 1.45 & \multirow{3}{*}{1.485} & \multirow{3}{*}{0.223} \\
\hline Male & 247 & 9 & 3.64 & & \\
\hline Total & 384 & 11 & 2.86 & & \\
\hline \multicolumn{6}{|l|}{ Age } \\
\hline$<2$ year & 25 & 0 & 0 & \multirow{4}{*}{3.397} & \multirow{4}{*}{0.183} \\
\hline $2-5$ years & 158 & 4 & 2.53 & & \\
\hline$>5$ years & 201 & 7 & 3.48 & & \\
\hline Total & 384 & 11 & 2.86 & & \\
\hline \multicolumn{6}{|l|}{ Body condition } \\
\hline Good & 153 & 4 & 2.61 & \multirow{4}{*}{0.112} & \multirow{4}{*}{0.945} \\
\hline Medium & 142 & 4 & 2.81 & & \\
\hline Poor & 89 & 3 & 3.37 & & \\
\hline Total & 384 & 11 & 2.86 & & \\
\hline
\end{tabular}

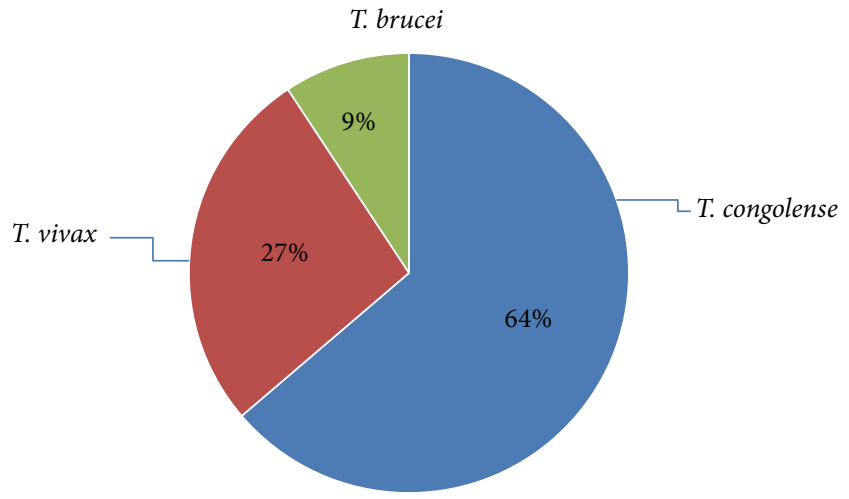

FIGURE 1: Distribution of the species of trypanosomes among the infected animals.

3.2. Cattle PCV Distribution in Studied Area. The frequency distribution of PCV \% for the overall studied 384 cattle is indicated in Figure 2. The mean PCV value of $27.7 \%$ was registered during the study period. The most frequently recorded PCV value was $28 \%$ and was recorded in 35 cattle from the overall studied animals in the district. The mean PCV values of cattle were significantly $(P=0.0011)$ influenced by trypanosome infection as 27.86 and $22.36 \%$ PCV values in trypanosome positive and trypanosome negative animals were registered, respectively (Table 2 ).

3.3. Prevalence of Trypanosomosis and Its Share in Prevalence of Cattle Anaemia. The overall anemia prevalence in the studied district was $19.27 \%$ (74/384). The anaemia prevalence was significantly higher in trypanosome positive cattle $(54.54 \%)$ than in noninfected cattle $(18.23 \%)(P<$ $0.05)$. Of $19.27 \%$ anaemia prevalence, $1.56 \%(6 / 384)$ was trypanosome infected animals. However, large number of animals $17.7 \%(68 / 384)$ had anaemia $(\mathrm{PCV}<24)$ without having trypanosome infection. Some animals 1.3\% (5/384)

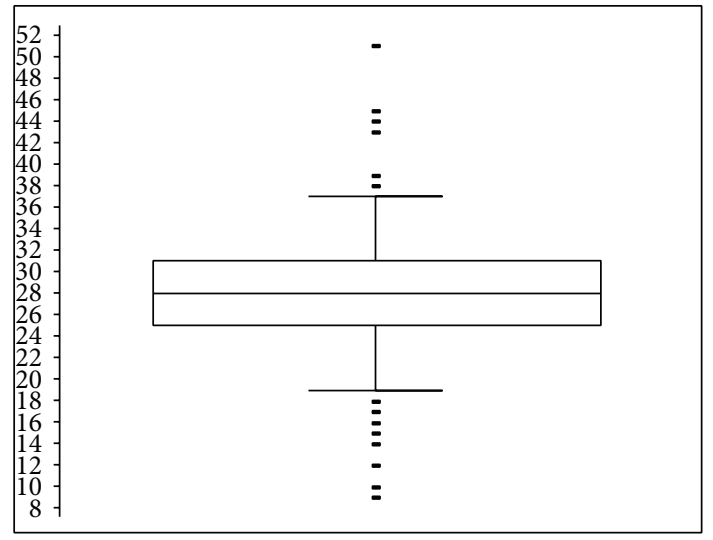

FIGURE 2: PCV distribution in cattle population of Dale Wabera district.

TABLE 2: Mean PCV comparison between infected and noninfected animals.

\begin{tabular}{lccccc}
\hline Condition & Number & Mean & SD & $t$-test & $P$ value \\
\hline Infected & 11 & 22.36 & 7.3929 & \multirow{2}{*}{3.3020} & 0.0011 \\
Noninfected & 373 & 27.86 & 5.3814 & & \\
\hline
\end{tabular}

were infected by trypanosome but their PCV was found normal (Table 3).

\section{Discussion}

The overall prevalence of bovine trypanosomosis in the study area was $2.86 \%$. The finding of the current study is lower than a range of studies conducted previously in Ethiopia: Tafese et al. [15] studied prevalence of bovine trypanosomosis in East Wollega zone using buffy coat technique and found prevalence rate of 8.5\%; Mekuria and Gadissa [16] reported $12.41 \%$ prevalence in Metekel and Awi zones of Northwest Ethiopia. Cherenet et al. [9], who assessed cattle trypanosomiasis in the tsetse-free and the tsetse-infested zones of the 
TABLE 3: Proportion of anaemia from trypanosome infected and noninfected cattle population.

\begin{tabular}{lcccc}
\hline Trypanosome & Anemia & Frequency & Percent & Percent share per strata \\
\hline \multirow{2}{*}{ Noninfected } & Negative & 305 & $79.4 \%$ & $81.8 \%$ \\
& Positive & 68 & $17.7 \%$ & $18.2 \%$ \\
\hline \multirow{2}{*}{ Infected } & Negative & 5 & $1.3 \%$ & $45.5 \%$ \\
& Positive & 6 & $1.5 \%$ & $54.5 \%$ \\
\hline
\end{tabular}

Amhara region of Northwestern Ethiopia using molecular diagnostic method, reported infection rates of $20.9 \%$ and $25.7 \%$, respectively. This result was also lower as compared to [6] at tsetse infested areas of Ethiopia (17.67\%); [17] in Dembecha and Jabitehenan (12\%); and [18] in Metekel district (17.20\%).

Lower prevalence was found in this study compared to the works of these authors elsewhere in the country. This disparity emanates from many factors that explain the lower trypanosomosis prevalence in the study area. There were parasite and vector control programmes practiced in the area. Also as the study was conducted during late rainy season it is obvious that the population of flies increases. Due to this farmers inject their animals with trypanocidal drugs and also use insecticide spray in this season better than any other time to minimize the effect of the disease. These results in the lower prevalence of trypanosomosis observed in this study. In addition, expansion of veterinary services up to peasant association and deforestation for crop cultivation and settlement might also have contributed to the low prevalence. The lower prevalence observed in this study could also be due to inadequacy of parasite detection method used. It was reported that the buffy coat microscopy technique is relatively an insensitive diagnostic method as it fails to detect $66 \%$ of infected cattle [19]. The molecular diagnostic techniques which permit precise identification of the parasite to species level and serological diagnostic methods are more sensitive [20].

Out of the $2.86 \%$ overall prevalence of trypanosome infection, $1.82 \%$ were due to $T$. congolense, $0.78 \%$ were due to $T$. vivax, and $0.26 \%$ were due to $T$. brucei. The finding of this study showed that of the total trypanosome positive animals $63.6 \%$ were found to be infected with $T$. congolense, $27.2 \%$ were infected with $T$. vivax, and the remaining $9 \%$ were infected with T. brucei. In the current study mixed infection was not detected. The higher proportion of T. congolense in this study was in agreement with the previous results of [6] for tsetse infested areas of Ethiopia (58.5\%) and [21] at Mereb Abaya, South Ethiopia (66.1\%). Moreover, the results of [22] at Arba Minch Zuria districts (85.2\%) and [23] in Ghibe valley, Southwest Ethiopia (84\%), had also shown higher results of $T$. congolense.

The predominance of $T$. congolense infection in cattle suggests that the major cyclical vectors or Glossina species are more efficient transmitters of $T$. congolense than $T$. vivax in East Africa [24] and also due to the high number of serodems of $T$. congolense as compared to T. vivax and the development of better immune response to $T$. vivax by infected animals [25]. Different studies $[25,26]$ have indicated that T. vivax is highly susceptible to treatment while the problems of drug resistance are higher in $T$. congolense, and $T$. congolense is mainly confirmed in the blood, while T. vivax and T. brucei also invade the tissues [27]. According to [6], T. congolense and $T$. vivax are the most prevalent trypanosomes that infect cattle in tsetse infested and tsetse free areas of the Ethiopia, respectively.

The prevalence of bovine trypanosomosis was studied in different sex, body condition, and age groups of cattle and significant variation was not observed $(P>0.05)$. This might be because of an equal chance of exposure to the parasite. This result is in agreement with the previous researches reported by $[10,12,15,28]$. In the present study sex was not found to be the risk factor. This finding could be during late rainy season as plough stress for males reduced; both males and females can be affected uniformly in high tsetse challenge areas.

The overall anaemia prevalence in the studied district was $19.27 \%$. When infected and noninfected animals were compared, the anaemia prevalence was significantly higher in trypanosome positive cattle $(6 / 11,54.54 \%)$ than in noninfected cattle $(68 / 373,18.23 \%)(P<0.05)$. This finding was in agreement with previous reports $[9,10,28]$. Of total anaemia prevalence $(19.27 \%), 1.56 \%$ was trypanosome positive animals. However, large number of animals, $17.7 \%$, had anaemia without having trypanosomosis infection. This suggests that even though anaemia is characteristic of trypanosomosis, other factors are also anticipated to affect the PCV profile of animals. Diseases such as fasciolosis, gastrointestinal parasitism, vector-borne diseases, and nutritional deficiencies can also cause reduced PCV [29]; however there were no previous published research reports of these diseases in the studied area.

Some animals were infected by trypanosome but their PCV was normal and anaemia was not recorded in them. This might be due to some infected animals being able to keep their PCV within the normal range for a certain period of time. The appearance of parasitologically negative animals with PCV values of less than the threshold value set (24\%) may be due to inadequacy of the detection method used [20], other anaemia causing diseases [29], or delayed recovery of the anaemic situation after current treatment with trypanocidal drugs. Furthermore, the occurrence of positive animals with PCV of greater than $24 \%$ might be thought of as recent infections of the animals [29].

The mean PCV value of parasitemic animals was found to be significantly lower $(22.36 \% \pm 7.39)$ than that of aparasitemic $(27.86 \% \pm 5.38)$ animals which is similar to the results obtained by $[9,28,30]$. Taking the PCV value 24 to $46 \%$ as normal for zebu cattle [31], 54.5\% of the parasitemic and $18.2 \%$ aparasitemic animals have registered PCV values less than $24 \%$. Low PCV value may not solely be due to 
trypanosomosis. However, these factors are likely risks for both parasitaemic and nonparasitaemic animals. Therefore the difference in mean PCV value between parasitemic and aparasitemic animals indicates that trypanosomosis is involved in reducing the PCV values in the infected animals.

\section{Conclusion}

This study indicated that trypanosomosis is an important disease and a potential threat that affects the health and productivity of cattle in Dale Wabera district. The major species of trypanosomes in the study area were T. congolense followed by T. vivax and T. brucei. Nearly $20 \%$ of the sampled animals had a PCV value of below $24 \%$ and were thus considered as anaemic. The anaemia prevalence was significantly higher in trypanosome positive cattle than in noninfected cattle. The mean PCV value of parasitemic animals was significantly lower $(22.36 \% \pm 7.39)$ than that of aparasitemic $(27.86 \% \pm$ 5.38 animals. This indicates that infection with trypanosomosis negatively affects PCV profile of animals. Therefore, proper strategies have to be designed and implemented to minimize its effect on livestock production in the studied area.

\section{Conflict of Interests}

The authors declare that there is no conflict of interests regarding the publication of this paper.

\section{Acknowledgments}

The authors are grateful to National Tsetse and Trypanosomiasis Investigation and Control Center for provision of logistics.

\section{References}

[1] D. M. Bourn, R. S. Reid, D. J. Rogers, W. F. Shnow, and G. R. W. Wint, Environmental Change and the Autonomous Control of Tsetse and Trypanosomosis in Sub-Saharan Africa: Case Histories from Ethiopia, Gambia, Kenya, Nigeria and Zimbabwe, Environmental Research Group Oxford Limited, Oxford, UK, 2001.

[2] T. N. Baral, "Immunobiology of African trypanosomes: need of alternative interventions," Journal of Biomedicine and Biotechnology, vol. 2010, Article ID 389153, 24 pages, 2010.

[3] F. A. S. Kuzoe, "Current situation of African trypanosomiasis," Acta Tropica, vol. 54, no. 3-4, pp. 153-162, 1993.

[4] OIE, "Standardized techniques for the diagnosis of tsetse transmitted trypanosomiasis," in OIE Terrestrial Manual, p. 49, OIE, Rome, Italy, 2008.

[5] IAEA, Workshop on Strategic Planning of Area Wide Tsetse and Trypanosomiasis Control in West Africa May, 21-4, 2001, Ouagadougou, Burkinafaso, 2002.

[6] G. Abebe and Y. Jobre, "Trypanosomiasis : a threat to cattle production in Ethiopia," Revue de Medecine Veterinaire, vol. 147, no. 12, pp. 897-902, 1996.
[7] "National Tsetse and Trypanosomiasis Investigation and Control Center (NTTICC)," Annual Report NTTICC, Bedele, Ethiopia, 2004.

[8] H. M. Lemecha, "Trypanosomosis research and control in Ethiopia: an overview," in Proceedings of the 8th Annual Conference of the Ethiopian Veterinary Association, pp. 7-12, Addis Ababa, Ethiopia, 1994.

[9] T. Cherenet, R. A. Sani, N. Speybroeck, J. M. Panandam, S. Nadzr, and P. van den Bossche, "A comparative longitudinal study of bovine trypanosomiasis in tsetse-free and tsetseinfested zones of the Amhara Region, northwest Ethiopia," Veterinary Parasitology, vol. 140, no. 3-4, pp. 251-258, 2006.

[10] A. Mihret and G. Mamo, "Bovine trypanosomosis in three districts of East Gojjam Zone bordering the Blue Nile River in Ethiopia," Journal of Infection in Developing Countries, vol. 1, no. 3, pp. 321-325, 2007.

[11] N. Kebede and A. Animut, "Trypanosomosis of cattle in selected districts of Awi zone, northwestern Ethiopia," Tropical Animal Health and Production, vol. 41, no. 7, pp. 1353-1356, 2009.

[12] T. Abebayehu, H. Eset, M. Berhanu, A. Rahmeto, and M. Solomon, "Mechanically transmitted bovine trypanosomosis in Tselamity wereda, Western Tigray, Northern Ethiopia," Agricultural Journal, vol. 6, no. 1, pp. 10-13, 2011.

[13] M. J. Nicholson and M. H. Butterworth, A Guide to Condition Scoring of Zebu Cattle, International Livestock Center for Africa (ILCA), 1986.

[14] M. Thrustfield, Veterinary Epidemiology, Black Well Science, London, UK, 3rd edition, 2005.

[15] W. Tafese, A. Melaku, and T. Fentahun, "Prevalence of bovine trypanosomosis and its vectors in two districts of East Wollega zone, Ethiopia," The Onderstepoort Journal of Veterinary Research, vol. 79, pp. 123-128, 2012.

[16] S. Mekuria and F. Gadissa, "Survey on bovine trypanosomosis and its vector in Metekel and Awi zones of Northwest Ethiopia," Acta Tropica, vol. 117, no. 2, pp. 146-151, 2011.

[17] D. Shimelis, A. K. Sangwan, and A. Getachew, "Epidemiology of tsetse transmitted trypanosomosis in Abay (Blue Nile) basin of Northwest Ethiopia," Revue d'Élevage et de Médecine Vétérinaire des Pays Tropicaux, vol. 58, pp. 151-157, 2005.

[18] A. Yohanes, Field investigation on appearance of drug resistant population of trypanosomes in Metekel districts, Northwest Ethiopia [M.S. thesis], Freie University, Berlin, Germany, 1997.

[19] T. Marcotty, H. Simukoko, D. Berkvens, J. Vercruysse, N. Praet, and P. van den Bossche, "Evaluating the use of packed cell volume as an indicator of trypanosomal infections in cattle in eastern Zambia," Preventive Veterinary Medicine, vol. 87, no. 34, pp. 288-300, 2008.

[20] M. Murray, P. K. Murray, and W. I. M. Mclntyre, "An improved technique for the diagnosis of African trypanosomosis," Transactions of the Royal Society of Tropical Medicine and Hygiene, vol. 71, no. 4, pp. 325-326, 1977.

[21] K. S. Muturi, Epidemiology of bovine trypanosomosis in selected sites of the Southern rift valley of Ethiopia [M.S. thesis], Addis Ababa University, with Freie University at Berlin, 1999.

[22] G. Woldeyes and G. Aboset, "Tsetse and trypanosomosis distribution, identification and assessment of socio-economic viabilities of the new vector control approaches in Arbaminch Zuria woreda," in Proceedings of the EVA Proceedings of the 11th Conference, pp. 143-154, 1997.

[23] G. J. Rowlands, W. Mulatu, S. G. A. Leak, S. M. Nagda, and G. D. M. D'Ieteren, "Estimating the effects of tsetse control 
on livestock productivity-a case study in Southwest Ethiopia," Tropical Animal Health and Production, vol. 31, no. 5, pp. 279294, 1999.

[24] W. P. Langridge, A Tsetse and Trypanosomiasis Survey of Ethiopia, Ministry of Overseas Development of British and Ministry of Agriculture of Ethiopia, Addis Ababa, Ethiopia, 1976.

[25] S. G. A. Leak, W. Malatu, E. Authie et al., "Epidemiology of bovine trypanosomiasis in the Ghibe valley, southwest Ethiopia. 1. Tsetse challenge and its relationship to trypanosome prevalence in cattle," Acta Tropica, vol. 53, no. 2, pp. 121-134, 1993.

[26] G. J. Rowlands, W. Mulatu, S. M. Nagda, R. B. Dolan, and G. D. M. d'Ieteren, "Genetic variation in packed red cell volume and frequency of parasitaemia in East African Zebu cattle exposed to drug-resistant trypanosomes," Livestock Production Science, vol. 43, no. 1, pp. 75-84, 1995.

[27] L. E. Stephen, Trypanosomiasis, A Veterinary Perspective, Pergamon Press, Oxford, UK, 1986.

[28] M. Bekele and M. Nasir, "Prevalence and host related risk factors of bovine trypanosomosis in Hawagelan district, West Wellega zone, Western Ethiopia," African Journal of Agricultural Research, vol. 6, no. 22, pp. 5055-5060, 2011.

[29] P. van den Bossche and G. J. Rowlands, "The relationship between the parasitological prevalence of trypanosomal infections in cattle and herd average packed cell volume," Acta Tropica, vol. 78, no. 2, pp. 163-170, 2001.

[30] S. Dagnachew, H. Girma, and G. Abebe, "A cross-sectional study on bovine trypanosomosis in Jawi district of Amhara Region, Northwest Ethiopia," Ethiopian Veterinary Journal, vol. 15, pp. 69-78, 2011.

[31] D. C. Blood and O. M. Radostits, Veterinary Medicine: A Text Book of Diseases of Cattle, Sheep, Pigs, Goats and Horses, Bailliere Tindall, 10th edition, 2007. 

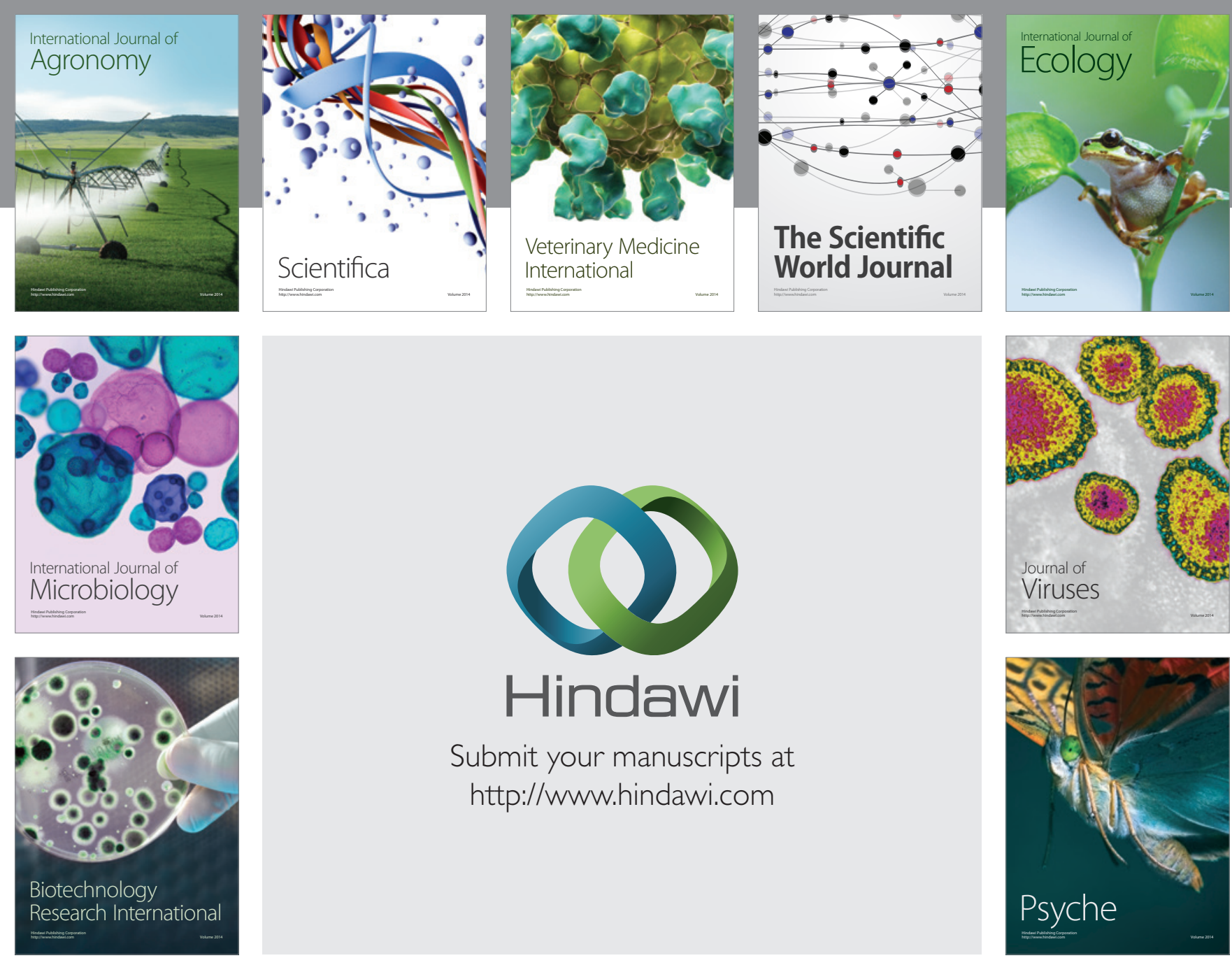

Submit your manuscripts at http://www.hindawi.com
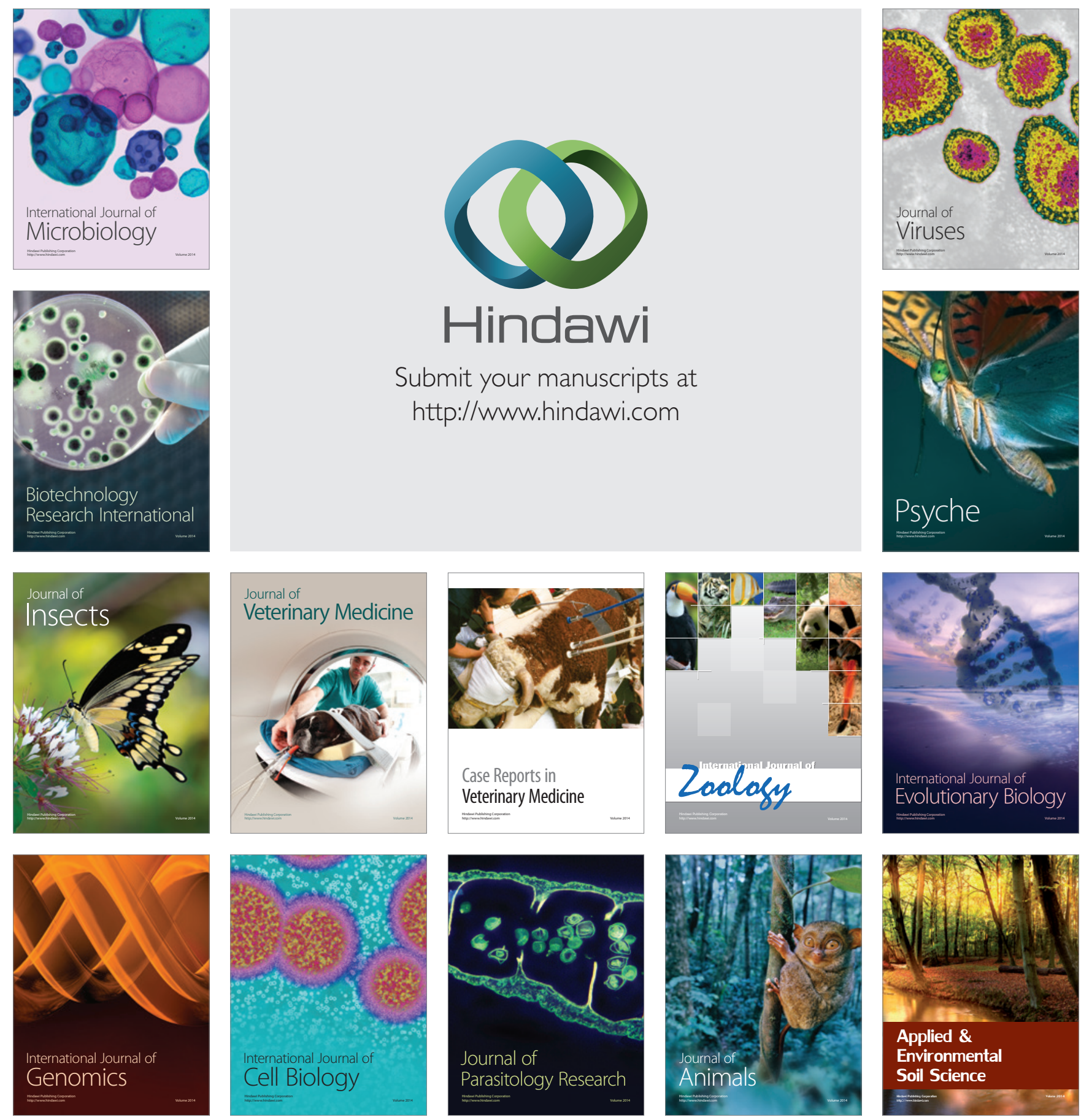